\title{
Energy and Exergy Analysis of LiBr-aq and LiCl-aq Liquid Desiccant Dehumidification System
}

\author{
Barış Kavasoğullari, Ertuğrul Cihan, Hasan Demir
}

\begin{abstract}
In this study, energy and exergy analysis of experimental results obtained from a dehumidification system using LiBr-aq (lithium bromide-water) and LiCl-aq (lithium chloridewater) as desiccant was made. In dehumidifier and regenerator columns polycarbonate sheets, which have not been used before, were used as packing material to increase contact area in purposed liquid desiccant dehumidification system. In the analysis, variation of electrical coefficient of performance and exergy efficiency with airflow rate for different solution mass flow rates were investigated. Because of investigation, maximum values of electrical coefficient of performance and exergy efficiency were calculated approximately as 2.8 and $18 \%$, respectively.
\end{abstract}

Keywords: energy; exergy; liquid desiccant; liquid desiccant dehumidification; polycarbonate packing

\section{INTRODUCTION}

Nowadays, vapor compression refrigeration systems are extensively used for heating/cooling processes. On the other hand, these types of systems are highly dependent on electrical energy and provide limited humidity control and indoor air quality. For this reason, researchers lead to alternative air conditioning systems.

Liquid desiccant dehumidification systems are good alternatives to the vapor compression systems commonly used in air conditioning processes. The operation of the system is based on the principle that air is brought into contact with a low vapor pressure liquid to remove moisture from the air. In this way, the amount of moisture in the air can be brought to an acceptable level by consuming very small amount of energy.

Although liquid desiccant dehumidification systems have a low coefficient of performance, they are more interesting for general daily usage due to temperature independent humidity control and better indoor air quality [14]. In addition, the dilute liquid solution after dehumidification in the system can be regenerated using medium and low-temperature heat sources such as industrial waste heat, solar energy and geothermal energy. The efficiency and the energy saving of the system can be further increased [5-7].

Ahmed et al. [8] carried out exergy analysis of a hybrid air conditioning system operating with liquid desiccant dehumidification system. Xiong et al. [9] also performed exergy analysis of a novel two-phased liquid desiccant dehumidification system and they compared that system with a single-phased dehumidification system. Zhang et al. [10] performed an exergy analysis with the heat and mass transfer analysis of the liquid dehumidification system using LiBrwater solution.

In this study, energy and exergy analysis of a liquid desiccant dehumidification system for two liquid desiccant solutions, which are $\mathrm{LiBr}$ and $\mathrm{LiCl}$, was experimentally conducted. The electrical coefficient of performance and exergy efficiency were chosen as performance parameters and two solutions were compared according to these parameters.

\section{SYSTEM DESCRIPTION}

In liquid desiccant dehumidification systems, moisture in the air is removed by strong desiccant solutions which are hygroscopic materials. The dehumidification process depends on water vapor pressure difference between liquid desiccant and air. After dehumidification process, diluted solution is regenerated by the regenerator column.

The tested liquid desiccant dehumidification system is shown schematically in Fig. 1. The system consists of dehumidification and regenerator columns, air fans, liquid pumps, heat exchangers and various sensors.

In liquid desiccant dehumidification system, process air enters at point (1) and leaves the dehumidifier at point (3) after its moisture is removed. In the dehumidifier column, strong liquid desiccant solution, which takes some moisture from the air, becomes diluted. Diluted liquid desiccant solution is sent to the regenerator column with the aid of liquid pump at point (8). Before it enters the regenerator column, solution is heated using heating HEx at point (9). Afterwards, the solution is regenerated by passing air through (points 4-6). Regenerated solution is cooled to reduce the surface vapor pressure by cooling HEx (point 12) before it is reused in dehumidifier.

In the tested system, various sensors were placed at specified points to measure temperature, relative humidity, flow rates and pressure difference (Fig. 1). Air flow rates were measured with KIMO-CTV210 ( $\pm 0.3 \%$ sensitivity $)$ sensor, liquid flow rates were measured with GF Signet Capteur 515 sensor ( $\pm 0.5 \%$ sensitivity).

Relative humidity and temperature values of the air at inlet and outlet of dehumidifier and regenerator columns were measured with Vaisala HMT120 $( \pm 1.5 \%$ RH and \pm 0.2 ${ }^{\circ} \mathrm{C}$ sensitivity) sensor. Liquid desiccant, hot and cold water temperatures used in HEx's were measured with $\mathrm{K}$ type thermocouple $\left( \pm 0.4 \%{ }^{\circ} \mathrm{C}\right.$ sensitivity).

In the tested system, novel structured polycarbonate packing materials were used to increase air-solution contact 
area and time. Polycarbonate packing materials were formed by cutting large polycarbonate sheets of $2 \times 6 \mathrm{~m}$ in dimensions of $100 \times 300 \times 6 \mathrm{~mm}$ and channel angles of $30^{\circ}$. Formed polycarbonate sheets and their placement in columns were shown in Fig. $2 a$ and $2 b$ respectively. The polycarbonate sheets were placed in such a way that the channels would form a zig-zag so that the contact time could be increased, and a smooth flow could be obtained. Average surface area density of the sheets was calculated as 637 $\mathrm{m}^{2} / \mathrm{m}^{3}$.
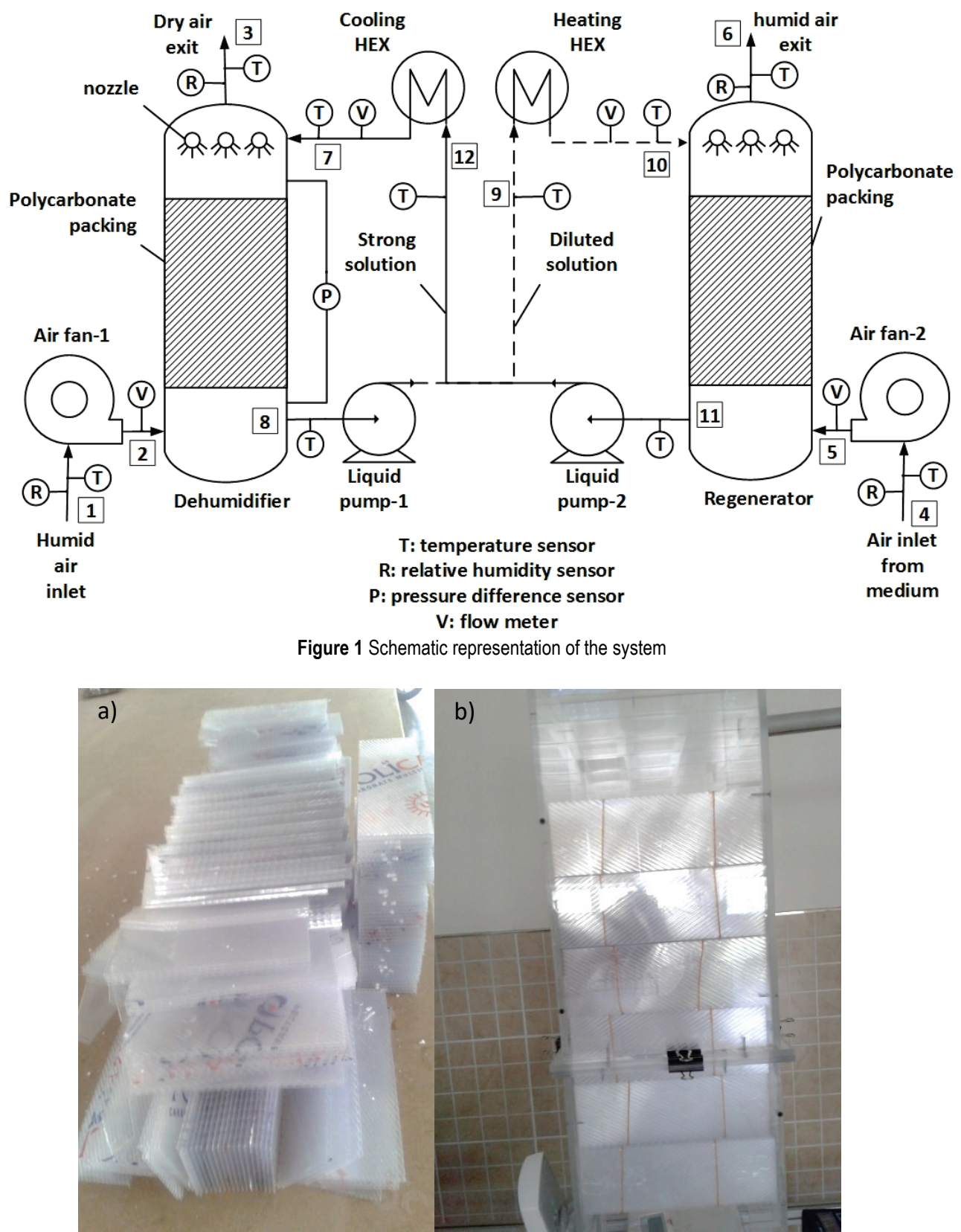

Figure 2 a) Formed polycarbonate sheets, b) placement of sheets in columns

\section{ENERGY AND EXERGY CALCULATIONS}

In the study, electrical coefficient of performance and exergy efficiency were used to investigate performance of the system. Calculations were carried out by EES (Engineering equation solver) software [11].

Electrical coefficient of performance of the system was calculated by Eq. (1):
$C O P_{\mathrm{e}}=\frac{\dot{Q}_{\mathrm{ev}}}{\dot{W}_{\mathrm{e}}}$

Here, $\dot{Q}_{\text {ev }}$ and $\dot{W}_{\mathrm{e}}$ are recovered heat energy and consumed electrical energy in unit time respectively. $\dot{Q}_{\mathrm{ev}}$ was found from the following equation: 
$\dot{Q}_{\mathrm{ev}}=\dot{m}_{\mathrm{a} 1}\left(\omega_{2}-\omega_{3}\right) \Delta h_{\mathrm{fg}}$

In Eq. (2), $\dot{m}_{\mathrm{a} 1}, \omega_{2}$ and $\omega_{3}$ represent mass flow rate of air $(\mathrm{kg} / \mathrm{s})$, inlet and outlet absolute humidity of air $\left(\mathrm{kg}_{\mathrm{H} 2 \mathrm{O}} / \mathrm{kg}_{\text {DryAir }}\right)$ in dehumidifier respectively. $\Delta h_{\mathrm{fg}}$ is the latent heat $(\mathrm{kJ} / \mathrm{kg})$ of water. In the purposed system, specific exergy flow $(\mathrm{kJ} / \mathrm{kg})$ of any point was calculated by Eq. (3):

$\psi_{i}=h_{i}-h_{0}\left[T_{0}\left(s_{i}-s_{0}\right)\right]$

Here, "0" subscript represents the dead state. Exergy loss of the dehumidifier was found by Eq. (4):

$$
\dot{E}_{\mathrm{ab}}=\dot{m}_{\mathrm{a} 1}\left(\psi_{2}-\psi_{3}\right)+\dot{m}_{\mathrm{s} 1}\left(\psi_{7}-\psi_{8}\right)
$$

In Eq. (4), $\dot{m}_{\mathrm{s} 1}$ is mass flow rate $(\mathrm{kg} / \mathrm{s})$ of the desiccant solution in dehumidifier column. Exergy losses in the cooling and heating HEx's were calculated by Eq. (5) and (6) respectively:

$$
\begin{aligned}
& \dot{E}_{\mathrm{hexc}}=\dot{m}_{\mathrm{s} 1}\left(\psi_{12}-\psi_{7}\right)+\dot{m}_{\mathrm{cw}}\left(\psi_{\mathrm{swi}}-\psi_{\mathrm{cwo}}\right) \\
& \dot{E}_{\mathrm{hexh}}=\dot{m}_{\mathrm{s} 2}\left(\psi_{10}-\psi_{9}\right)+\dot{m}_{\mathrm{hw}}\left(\psi_{\mathrm{hwi}}-\psi_{\mathrm{hwo}}\right)
\end{aligned}
$$

In Eq. (5), $\dot{m}_{\mathrm{cw}}$ and $\dot{m}_{\mathrm{hw}}$ are the mass flow rate $(\mathrm{kg} / \mathrm{s})$ of the cold and hot water respectively. Subscripts "cwi" and "cwo" refer inlet and outlet status of the water in cooling HEx. Similarly, "hwi" and "hwo" represent inlet and outlet status of the water in heating HEx. $\dot{m}_{\mathrm{s} 2}$ is mass flow rate $(\mathrm{kg} / \mathrm{s})$ of the desiccant solution at heating HEx and regenerator. Exergy loss of the regenerator was found by the following equation:

$\dot{E}_{\text {rej }}=\dot{m}_{\mathrm{a} 2}\left(\psi_{5}-\psi_{6}\right)+\dot{m}_{\mathrm{s} 2}\left(\psi_{11}-\psi_{10}\right)$

Here, $\dot{m}_{\mathrm{a} 2}$ refers the mass flow rate $(\mathrm{kg} / \mathrm{s})$ of the air at regenerator. Exergy efficiency of the system was defined by Eq. (8):

$n_{\text {system }}=\frac{\dot{E}_{\mathrm{k}}}{\dot{E}_{\mathrm{hw}}}$

In Eq. (8) $\dot{E}_{\mathrm{k}}$ and $\dot{E}_{\mathrm{hw}}$ are gained exergy (kW) by process air in dehumidifier and consumed exergy $(\mathrm{kW})$ to regenerate the diluted solution in regenerator respectively. These parameters were calculated by following equations:

$$
\begin{aligned}
& \dot{E}_{\mathrm{k}}=\dot{m}_{\mathrm{a} 1}\left(\psi_{3}-\psi_{2}\right) \\
& \dot{E}_{\mathrm{hw}}=\dot{m}_{\mathrm{hw}} c p_{\mathrm{w}}\left(T_{\mathrm{hwi}}-T_{\mathrm{hwo}}\right)\left(\frac{T_{\mathrm{hwi}}-T_{\mathrm{wt}}}{T_{\mathrm{hwi}}}\right)
\end{aligned}
$$

In Eq. (10), $T_{\mathrm{wt}}$ and $c p_{\mathrm{w}}$ represent dead state temperature and average specific heat of the water, respectively.

\section{$4 \quad$ RESULTS AND DISCUSSION}

In the liquid desiccant dehumidification system, energy and exergy analysis were conducted for $43 \%$ wt LiBr-water and LiCl-water solutions separately. Calculations were performed with the aid of EES software according to experimental results. Measured and specified experimental parameters and dead state properties were shown in Tab. 1 $[10,12]$. In experimental rig, ARGAL P 06.10 chemical centrifugal pump was used as liquid pump and it operates in between $0-6.3(\mathrm{~kg} / \mathrm{s})$. As it is visible in table, solution mass flow rates were selected as 1.42 and $1.85(\mathrm{~kg} / \mathrm{s})$, which are in operation range of the liquid pump. In the table, $T, P, \Phi$ and $X$ values refer to dead state properties of temperature, pressure, relative humidity and concentration, respectively.

Table 1 Experimental parameters and dead state properties

\begin{tabular}{|l|r|}
\hline \multicolumn{1}{|c|}{ Parameter } & \multicolumn{1}{c|}{ Measured/specified value } \\
\hline Liquid desiccants & $43 \% \mathrm{wt} \mathrm{LiBr}$ and LiCl solution \\
\hline Packing height, $\mathrm{cm}$ & 60 \\
\hline Average air flow rate, $\mathrm{m}^{3} / \mathrm{h}$ & $400,680,1000$ \\
\hline $\begin{array}{l}\text { Average solution mass flow rate, } \mathrm{kg} / \mathrm{s} \\
\text { (dehumidifier) }\end{array}$ & $1.42,1.85$ \\
\hline Cold water inlet/outlet temperature & $14 / 2{ }^{\circ} \mathrm{C}$ \\
\hline Hot water inlet/outlet temperature & $59.1 / 50.2^{\circ} \mathrm{C}$ \\
\hline $\begin{array}{l}\text { Average solution temperature } \\
\text { (dehumidifier) }\end{array}$ & $28.7{ }^{\circ} \mathrm{C}$ \\
\hline $\begin{array}{l}\text { Average solution temperature } \\
\text { (regenerator) }\end{array}$ & $45.8{ }^{\circ} \mathrm{C}$ \\
\hline Dead state properties of water & $T_{\mathrm{wt}}=25^{\circ} \mathrm{C}, P_{\mathrm{wt}}=101.3 \mathrm{kPa}$ \\
\hline Dead state properties of air & $T_{0}=25^{\circ} \mathrm{C}, P_{0}=101.3 \mathrm{kPa}, \Phi_{0}=99 \%$ \\
\hline Dead state properties of solution & $T_{\mathrm{s}}=30^{\circ} \mathrm{C}, X_{\mathrm{s}}=0.0001 \mathrm{~kg} / \mathrm{kg}$ \\
\hline
\end{tabular}

The distribution of total exergy loss in the system equipment for $\mathrm{LiBr}$-water solution at $1.42 \mathrm{~kg} / \mathrm{s}$ desiccant mass flow rate and $400 \mathrm{~m}^{3} / \mathrm{h}$ air flow rate was shown in Fig. 3. The maximum exergy loss occurred in heating HEx because of high regeneration temperature. In dehumidifier, high surface vapor pressure difference causes high exergy loss.

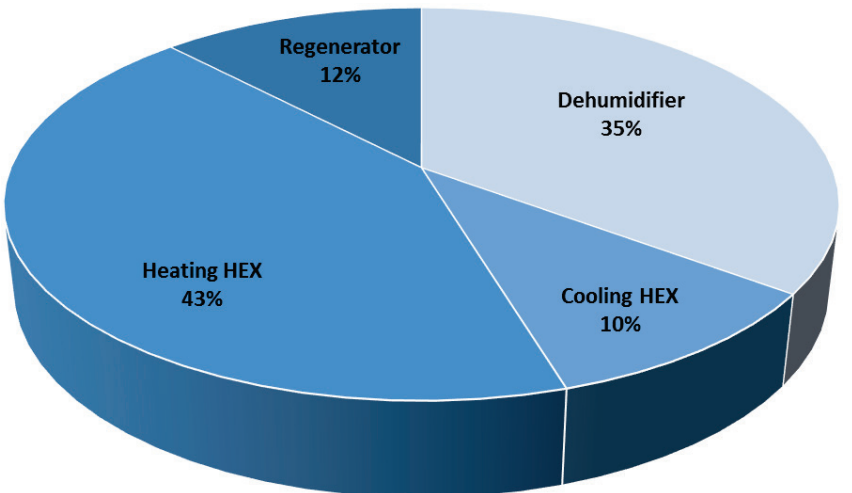

Figure 3 Distribution of total exergy loss over the equipment

Fig. 4 represents variation of absolute humidity of air in dehumidifier and regenerator columns for $\mathrm{LiBr}$-water solution at $1.42 \mathrm{~kg} / \mathrm{s}$ solution mass flow rate and $400 \mathrm{~m}^{3} / \mathrm{h}$ air flow rate. In the dehumidification process (2-3), air contacts with relatively hot and strong desiccant solution, hence its temperature increases and absolute humidity 
decreases. In the regeneration process (5-6), air contacts with hot and diluted solution; therefore, temperature and absolute humidity of air increase.

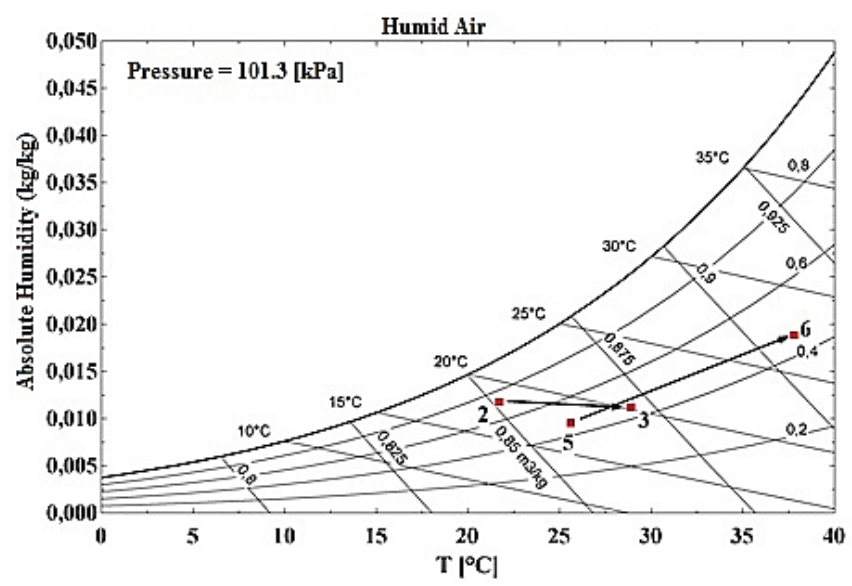

Figure 4 Variation of absolute humidity of air in dehumidifier and regenerator columns

Fig. 5 shows the variation of electrical coefficient of performance values for $\mathrm{LiBr}$-water and $\mathrm{LiCl}$-water at 1.42 $\mathrm{kg} / \mathrm{s}$ solution mass flow rate. During the experiments, mass flow rates of solutions were kept constant at $1.42 \mathrm{~kg} / \mathrm{s}$ and airflow rates increased from 400 to $1000 \mathrm{~m}^{3} / \mathrm{h}$. As it can be seen from the figure, increase in airflow rates will increase the electrical coefficient of performance for both solutions. Since LiCl-water solution has lower surface vapor pressure than LiBr-water, amount of removed moisture $\left(\dot{Q}_{\mathrm{ev}}\right)$ will be higher as well as electrical coefficient of performance. The maximum value of electrical coefficient of performance was obtained as 2.6 at $1000 \mathrm{~m}^{3} / \mathrm{h}$ airflow rate for $\mathrm{LiCl}$-water solution.

In Fig. 6, variation of electrical coefficient of performance was shown for both solutions at $1.85 \mathrm{~kg} / \mathrm{s}$ solution mass flow rate. The increase in the liquid desiccant flow rate caused a significant increase in the $\mathrm{LiCl}$ solution and insignificant change in the electrical coefficient of performance values in the $\mathrm{LiBr}$ solution. The maximum value was obtained with $\mathrm{LiCl}$ solution as 2.8 at $1000 \mathrm{~m}^{3} / \mathrm{h}$ airflow rate.

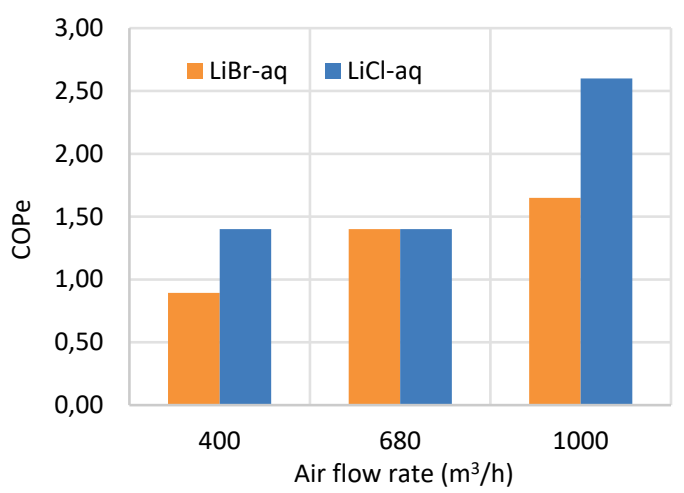

Figure 5 Variation of electrical coefficient of performance with air flow rate $\left(\dot{m}_{\mathrm{s} 1}=1.42 \mathrm{~kg} / \mathrm{s}\right)$

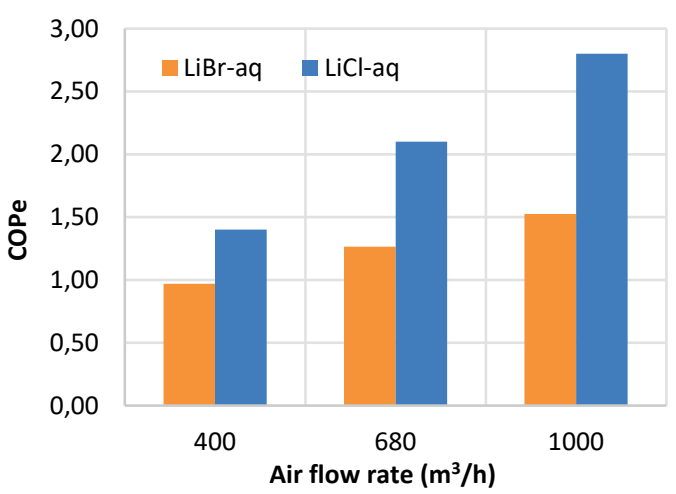

Figure 6 Variation of electrical coefficient of performance with air flow rate $\left(\dot{m}_{\mathrm{s} 1}=1.85 \mathrm{~kg} / \mathrm{s}\right)$

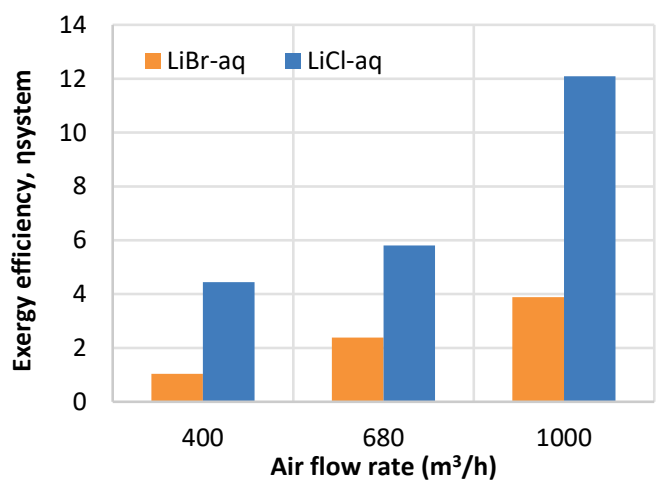

Figure 7 Variation of exergy efficiency values with air flow rate $\left(\dot{m}_{\mathrm{s} 1}=1.42 \mathrm{~kg} / \mathrm{s}\right)$

Fig. 7 shows the variation of exergy efficiency values for $\mathrm{LiBr}$-water and $\mathrm{LiCl}$-water solutions with airflow rates at constant $1.42 \mathrm{~kg} / \mathrm{s}$ solution mass flow rates. Since exergy efficiency values are highly dependent on amount of removed moisture, LiCl-water solution shows the best performance between two solutions. Airflow rate positively affects the exergy efficiency values for both solutions and the maximum value of about $12 \%$ was obtained at $1000 \mathrm{~m}^{3} / \mathrm{h}$ airflow rate.

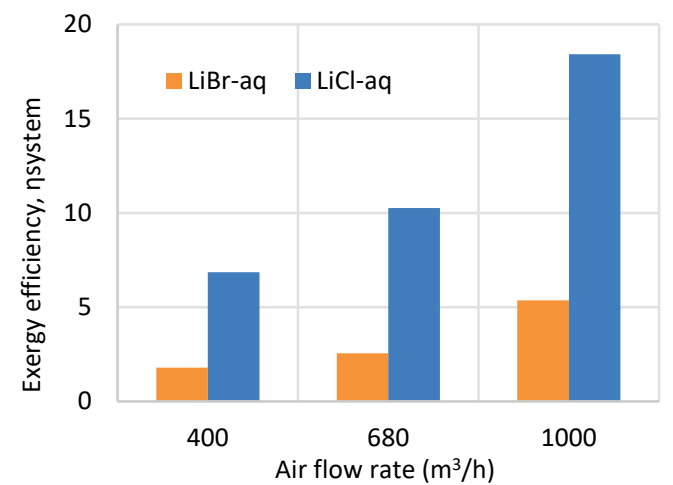

Figure 8 Variation of exergy efficiency values with air flow rate $\left(\dot{m}_{\mathrm{s} 1}=1.85 \mathrm{~kg} / \mathrm{s}\right)$

Variation of exergy efficiency values with air flow rate at $1.85 \mathrm{~kg} / \mathrm{s}$ solution mass flow rates were represented in Fig. 8. Increase in solution mass flow rates enhances the exergy efficiency values for both solutions. As a result of 
calculations, the maximum exergy efficiency value was found at about $18 \%$ with $\mathrm{LiCl}$-water solution at $1000 \mathrm{~m}^{3} / \mathrm{h}$.

\section{CONCLUSION}

In this study, energy and exergy analysis of a liquid desiccant dehumidification system using LiBr-water and LiCl-water as desiccants was performed using the experimental test results. In the analysis, electrical coefficient of performance and exergy efficiency were chosen as performance parameters and variation of these parameters with air flow rate and solution mass flow rates were investigated. As a result of investigation the following results were obtained:

- In experiments conducted with $\mathrm{LiBr}$ in the system, the most exergy loss occurred in the heating HEx. By reducing the regeneration temperature, the exergy lost in the heat exchanger can be reduced. However, excess reduction in the regeneration temperature may cause decrease in regeneration performance of the system.

- According to the obtained electrical coefficient of performance values and exergy efficiencies, low surface vapor pressure provided by the $\mathrm{LiCl}$ solution will provide a great advantage in terms of performance in the system. In the analysis with $\mathrm{LiCl}$ solution, the highest electrical coefficient of performance and exergy efficiency values were determined by approximately 2.8 and $18 \%$ respectively, while the same parameters were determined to be approximately 1.6 and $5 \%$ with $\mathrm{LiBr}$ solution. The electrical coefficient of performance values obtained with both solutions show that the system uses the primary energy sources efficiently.

Considering the electrical coefficient of performance and exergy efficiencies obtained in the study, the $\mathrm{LiCl}$ solution comes to the fore, as mentioned before. However, in selecting the appropriate liquid desiccant to be used in the system, price and availability are important as well as the performance of the system. The LiBr solution offers lower initial investment and operational cost owing to its low price and high availability. For this reason, the use of the $\mathrm{LiBr}$ solution would be advantageous in these respects.

\section{Acknowledgement}

This study was supported by TÜBİTAK with project numbered 114M151.

\section{REFERENCES}

[1] Kavasoğulları, B., Cihan, E., \& Demir, H. (2016). Novel Packing Materials for Open Liquid Desiccant System. Energy Procedia, 91, 785-791. https://doi.org/10.1016/j.egypro.2016.06.244

[2] Ahmed, S., Gandhidasan, P., \& Al-Farayedhi, A. (1998). Thermodynamic analysis of liquid desiccants. Solar Energy, 62(1), 11-18. https://doi.org/10.1016/s0038-092x(97)00087-x

[3] Cihan, E., Kavasoğulları, B., \& Demir, H. (2017). Enhancement of performance of open liquid desiccant system with surface additive. Renewable Energy, 114, 1101-1112. https://doi.org/10.1016/j.renene.2017.08.002
[4] Yin, Y., Zheng, B., Yang, C., \& Zhang, X. (2015). A proposed compressed air drying method using pressurized liquid desiccant and experimental verification. Applied Energy, 141, 80-89. https://doi.org/10.1016/j.apenergy.2014.12.015

[5] Patnaik, S., Lenz, T., \& Löf, G. (1988). Experimental Studies with a Solar Open-Cycle Liquid Desiccant Cooling System. Advances in Solar Energy Technology, 1013-1018. https://doi.org/10.1016/b978-0-08-034315-0.50196-8

[6] Factor, H. M. \& Grossman, G. (1980). A packed bed dehumidifier/regenerator for solar air conditioning with liquid desiccants. Solar Energy, 24(6), 541-550. https://doi.org/10.1016/0038-092x(80)90353-9

[7] Katejanekarn, T., Chirarattananon, S., \& Kumar, S. (2009). An experimental study of a solar-regenerated liquid desiccant ventilation pre-conditioning system. Solar Energy, 83(6), 920933. https://doi.org/10.1016/j.solener.2008.12.006

[8] Ahmed, C. K., Gandhidasan, P., Zubair, S., \& Al-Farayedhi, A. (1998). Exergy analysis of a liquid-desiccant-based, hybrid air-conditioning system. Energy, 23(1), 51-59. https://doi.org/10.1016/s0360-5442(97)00040-6

[9] Xiong, Z., Dai, Y., \& Wang, R. (2010). Development of a novel two-stage liquid desiccant dehumidification system assisted by $\mathrm{CaCl} 2$ solution using exergy analysis method. Applied Energy, 87(5), 1495-1504. https://doi.org/10.1016/j.apenergy.2009.08.048

[10] Zhang, L., Liu, X., Jiang, J., \& Jiang, Y. (2014). Exergy calculation and analysis of a dehumidification system using liquid desiccant. Energy and Buildings, 69, 318-328. https://doi.org/10.1016/j.enbuild.2013.11.025

[11] Klein, S. A., Engineering Equation Solver, F-Chart Software, 2015. Academic Version 9.901.

[12] Xiong, Z. Q., Dai, Y. J., \& Wang, R. Z. (2010). Exergy Analysis of Liquid Desiccant Dehumidification System. International Journal of Green Energy, 7(3), 241-262. https://doi.org/10.1080/15435071003795881

\section{Authors' contacts: \\ Barış Kavasoğullarl, Res. Asst. (Corresponding author) \\ Osmaniye Korkut Ata University, Mechanical Engineering Department, Karacaoğlan Yerleşkesi Fakıuşağı Mah. 80000 Merkez/Osmaniye, Turkey Tel: +903288271000, Fax: +903288250097 E-mail: bkavasogullari@osmaniye.edu.tr}

Ertuğrul Cihan, Assoc. Prof. Osmaniye Korkut Ata University, Mechanical Engineering Department, Karacaoğlan Yerleşkesi Fakıuşağı Mah. 80000 Merkez/Osmaniye, Turkey Tel: +903288271000 , Fax: +903288250097

E-mail: ertugrul.cihan@osmaniye.edu.tr

Hasan Demir, Assoc. Prof. Osmaniye Korkut Ata University, Chemical Engineering Department, Karacaoğlan Yerleşkesi Fakıuşağı Mah. 80000 Merkez/Osmaniye, Turkey Tel: +903288271000, Fax: +903288250097 E-mail: hasandemir@osmaniye.edu.tr 